\title{
Broad-Scale Relations between Conservation Reserve Program and Grassland Birds: Do Cover Type, Configuration and Contract Age Matter?
}

\author{
Sam Riffell ${ }^{*}, 1$, Daniel Scognamillo ${ }^{2}$, L. Wes Burger, Jr. ${ }^{1}$ and Shawn Bucholtz ${ }^{3}$ \\ ${ }^{I}$ Department of Wildlife, Fisheries and Aquaculture, Mississippi State University, Mississippi State, MS 39762, USA \\ ${ }^{2}$ Arthur Temple College of Forestry and Agriculture, Stephen F. Austin State University, Box 6109, SFA Station, \\ Nacogdoches, TX 75962, USA; and ${ }^{3}$ USDA, Farm Service Agency, 1400 Independence Ave. SW, Washington, D. C. \\ 20250-0519, USA
}

\begin{abstract}
The Conservation Reserve Program (CRP) is a voluntary cropland set-aside program where environmentallysensitive cropland is retired to a conservation practice. Grassland birds should benefit because most CRP is grass habitat and because amount of land in CRP is highest in agriculture-dominated areas of the United States where grassland habitat has been most impacted. We used the Breeding Bird Survey and Common Land Unit (CLU) data (spatially-explicit data of farm field boundaries and land cover) to identify relations between types and configurations of CRP and grassland bird abundance in 3 Midwestern states. All 13 species we studied were related to at least one aspect of CRP habitat - specific conservation practices (e.g., native vs. exotic grass), CRP habitat configuration, or habitat age. Treating all types of CRP as a single habitat type would have obscured bird-CRP relations. Based on our results, creating a mosaic of large and small set-aside patches could benefit both area-sensitive and edge-associated grassland birds. Additionally, northern bobwhite and other birds that use early successional grasslands would benefit from periodic disturbances. CRP, agrienvironment schemes, and other government-sponsored set-aside programs may be most successful when administered as part of a targeted, regional conservation plan.
\end{abstract}

Keywords: Conservation reserve program, grassland birds, landscape relations, set-aside.

\section{INTRODUCTION}

Conservation benefits of agricultural land set-aside programs have been well-documented in both North America [1, 2] and Europe [3] despite lingering debate about the true extent and nature of these benefits [4-6]. Set-aside programs provide a variety of financial incentives (rental agreements, cost share, signup bonuses, etc.) for landowners to convert cropland to primarily grassland and forest land cover through government-administered contracts. The Conservation Reserve Program (CRP) is the largest set-aside program in the United States. Initiated as part of the Food Security Act of 1985 , the CRP was originally designed to control commodity production and reduce soil erosion, but has evolved through subsequent legislative modification. Now, environmental benefits and creation of wildlife habitat are explicit objectives of the CRP [1]. Approximately 15 million ha of potential wildlife habitat are currently enrolled under a CRP contract [7], and $\approx 80 \%$ of these CRP lands are enrolled in grass-based conservation practices [7]. Up to $0-15 \%$ of the total land area (and up to $25 \%$ of cropland) of some regions may have been converted from agriculture to less intensely managed habitats (Table 1). This has added wildlife habitat into some agriculture-dominated landscapes and modified aspects of landscape configuration [8]. Therefore, CRP land

*Address correspondence to this author at the Department of Wildlife, Fisheries \& Aquaculture, Box 9690, Mississippi State, MS 39762, USA; Tel: 6623250392; Fax: 6623258726; E-mail: sriffell@cfr.msstate.edu represents an important contributor to changes in the composition and configuration of some agricultural landscapes in the United States.

The CRP is a broad-scale conservation program with potential to help stabilize and possibly recover grassland bird populations. Almost $60 \%$ of North American grassland breeding bird species are declining [9], and these are the most consistently negative trends of any group of North American birds in recent decades [10-14]. The CRP targets agricultural regions where loss of native grassland habitat (and fragmentation of remnant grassland) is most severe and provides early successional grassland habitat in agricultural landscapes where natural grassland habitats have been most extensively altered. For example, northern bobwhite - experiencing one of the most geographically broad and steepest declines of any grassland birds [13] - require the interspersion of woody, grassland and crop habitats $[15,16]$ that the CRP often facilitates [8].

One important criterion for evaluating the ability of the Conservation Reserve Program (and other set-aside programs like agri-environment schemes) to provide bird habitat will be whether CRP habitat is associated with increased abundance of grassland birds at broad spatial scales (i.e., across ecological regions, nations and/or species' ranges [17]). Most existing evaluations of set-aside have focused primarily on individual fields or local scales [1, 2, 18 for reviews], and many of those that have assessed broad scale bird-CRP relations treat all CRP-enrolled lands (or at least 
Table 1. CRP Metrics Derived from the Farm Service Agency's Common Land Unit Database for Kansas, Missouri, and Nebraska

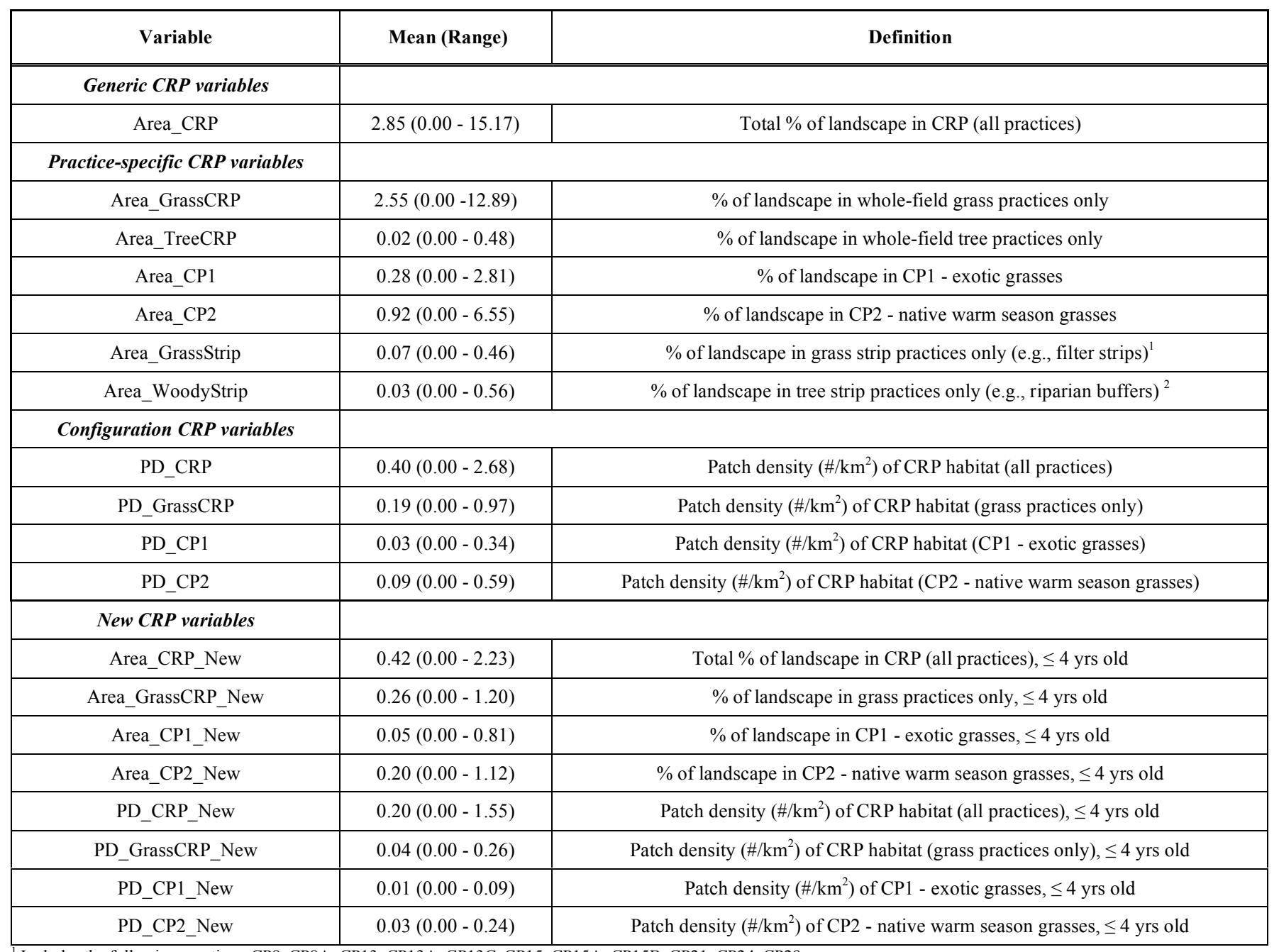

${ }^{1}$ Includes the following practices: CP8, CP8A, CP13, CP13A, CP13C, CP15, CP15A, CP15B, CP21, CP24, CP29.

${ }^{2}$ Includes the following practices: CP4A, CP4B, CP5, CP5A, CP13B, CP13D, CP16, CP16A, CP17, CP17A, CP22.

all grass practices) as a single habitat type [e.g., 10, 11, 1921].

Treating all CRP as one habitat type ignores ecologically important variation among different CRP practices and may thus obscure bird-CRP relations. First, different conservation practices (hereafter CPs) used by the CRP can vary in vegetation composition, structure, and subsequently, habitat quality (see Appendix 1 for a list). For example, tree plantings (CP3, CP11, etc.) in the Southeastern United States comprise over $60 \%$ of the CRP-enrolled [22]. Also, different grass practices can produce a variety of different habitats. Native grasses (CP2) may be better habitat than exotic grasses (CP1) for some species [23]. Similarly, the specific practices used in European agri-environment schemes vary from country to country $[6,18]$, and birds do not use all types of set-asides in these schemes equally [24, 25]. Second, the spatial arrangement of CRP patches has rarely been considered $[26,27]$. CRP plantings that are contiguous to each other or within a few kilometers may be more or less suitable as habitat than the same acreage widely dispersed. Landscape context (proportional composition and structure of the remainder of the landscape) may also influence the relative value of CRP as wildlife habitat [28]. Third, the age of the CRP planting can influence bird use of CRP. Vegetation communities in CRP fields are not static but change over the life of the contract, and the habitat value of CRP may vary with time since establishment [29-31]. For example, grass plantings are most suitable for northern bobwhite during the first 3 years of the enrollment [29]. Succession may render the habitat less suitable unless appropriate management activities (planned disturbance regimes) take place during the contract period $[32,33]$.

Our objective was to advance knowledge about bird-CRP relations by using more detailed descriptions of CRP than those used in previous research. We used the Common Land Unit (CLU) database - a spatially-explicit, national database of farm fields (including those with CRP contracts) currently being developed by the USDA Farm Service Agency - to describe the conservation practice type, spatial configuration, and age of CRP habitat in agricultural landscapes. These explicit CRP descriptions will allow the effects of specific practices, various spatial configurations and contract age to be included in CRP assessments, future modifications to the administration of the CRP, and in regional management strategies. 


\section{MATERIALS AND METHODOLOGY}

\section{Breeding Bird Data}

We restricted our analysis to Kansas, Missouri and Nebraska because these were the only states for which Common Land Unit (CLU) data were available (see Landscape and CRP Metrics below). We used grassland bird abundance data from the North American Breeding Bird Survey (BBS) a long-term monitoring program started in 1966 that includes $>4,000$ routes in North America that are annually counted during the breeding season $[9,34]$. Located along secondary roads $(<1-2$ vehicles / $\mathrm{min}$ ), routes do not usually include interstate, federal, state highways, or busy county roads [9, $34,35]$. Each $39.4-\mathrm{km}$ route consists of 50 stops $(0.8-\mathrm{km}$ intervals). Trained observers record all birds seen or heard at each stop during a 3-min period.

We calculated the mean abundance of each species over the 5-year window corresponding to the dates of the CLU database (2000 - 2004, see below) for all routes which were sampled in $\geq 3$ of the 5 years. This time period corresponded to the 4-year period of CRP initiation dates that we used to calculate metrics for early successional CRP (see below). We reduced (but did not entirely eliminate) the potential effects of heterogeneous detectability by averaging over multiple years, omitting route-year combinations with unacceptable conditions (e.g., inappropriate weather) or first-time observers following Sauer et al. [9], and by not making any comparisons among species. Additionally, we did not model any species that belongs to a group (e.g., raptors, nocturnal species, shorebirds, etc.) not effectively sampled by Breeding Bird Survey protocols [36]. This left us with 87 usable routes.

We analyzed abundance of 13 grassland-associated species that were present across the majority of our study area.
These species included 4 obligate grassland species [37] horned lark, grasshopper sparrow, dickcissel, and eastern meadowlark; 7 facultative grassland species [37] - northern bobwhite, mourning dove, eastern kingbird, common yellowthroat, lark sparrow, red-winged blackbird, eastern bluebird; a nest parasite - brown-headed cowbird; and an edge species - indigo bunting. Scientific names are listed in Table 3.

\section{Landscape and CRP Metrics}

To characterize the amount and distribution of CRP habitat, we used the Farm Service Agency's (FSA) Common Land Unit (CLU) database - a spatially-explicit database of farm fields that includes information on participation in the CRP (www.fsa.usda.gov). The CLU and the associated CRP participation data were used to construct GIS layers that identify the conservation practice, year of implementation (age of set-aside) and spatial information for every CRP contract in our study area circa 2004. This detail of associated data - especially the spatial information - is a unique feature of the CLU relative to other sources of information about the CRP.

We described characteristics of the surrounding landscape using the USGS National Land Cover Dataset (NLCD) and CRP characteristics using the FSA-CLU database. We used the CLU to mask the NLCD and exclude areas of the NLCD that overlapped with CRP contracts. Masking ensured that the NLCD-derived variables were mutually-exclusive of CLU-derived CRP variables (e.g., NLCD grassland did not include any CRP grassland).

We estimated landscape and CRP metrics within 1,962$\mathrm{km}^{2}$ (25-km radius), circular landscapes centered on the geometric center of each of the 87 usable BBS routes in our

Table 2. Landscape Variables and Eigenvectors for the First 5 Principal Components Used in Constructing Bird-Landscape Models

\begin{tabular}{|c|c|c|c|c|c|c|c|c|}
\hline Landscape Variables & Units & Mean & Range & LC1 & LC2 & LC3 & LC4 & LC5 \\
\hline Water & $\%$ & 1.15 & $0.02-5.39$ & 0.15 & 0.15 & 0.29 & 0.40 & 0.07 \\
\hline Urban & $\%$ & 1.34 & $0.00-16.29$ & 0.17 & 0.07 & 0.05 & 0.27 & 0.55 \\
\hline Forest & $\%$ & 18.55 & $0.01-88.87$ & -0.01 & 0.50 & 0.20 & -0.33 & -0.23 \\
\hline Grassland & $\%$ & 28.18 & $0.20-96.30$ & -0.20 & -0.51 & 0.04 & 0.13 & -0.29 \\
\hline Pasture/Hay & $\%$ & 18.80 & $0.02-64.41$ & 0.19 & 0.47 & 0.18 & 0.17 & 0.14 \\
\hline Rowcrops & $\%$ & 27.03 & $0.00-84.88$ & 0.16 & -0.23 & -0.39 & -0.00 & 0.52 \\
\hline Wetland & $\%$ & 1.61 & $0.00-8.46$ & 0.03 & -0.09 & 0.14 & 0.64 & -0.25 \\
\hline Forest Patch Density $^{1}$ & $\# / \mathrm{km}^{2}$ & 7.65 & $0.03-22.24$ & 0.36 & 0.06 & -0.43 & -0.18 & -0.12 \\
\hline Forest Edge Density $^{1}$ & $\mathrm{~m} / \mathrm{km}^{2}$ & 31.30 & $0.05-80.40$ & 0.32 & 0.15 & -0.40 & 0.19 & -0.29 \\
\hline Forest Mean Patch Size ${ }^{1}$ & ha & 3.30 & $0.12-36.33$ & -0.25 & -0.09 & 0.32 & -0.23 & 0.31 \\
\hline Grassland Patch Density $^{1}$ & $\# / \mathrm{km}^{2}$ & 9.51 & $0.30-35.98$ & 0.42 & -0.25 & 0.22 & -0.04 & 0.03 \\
\hline Grassland Edge Density $^{1}$ & $\mathrm{~m} / \mathrm{km}^{2}$ & 45.90 & $1.13-123.25$ & 0.42 & -0.19 & 0.28 & -0.23 & -0.07 \\
\hline Grassland Mean Patch Size $^{1}$ & ha & 13.68 & $0.18-322.50$ & -0.44 & 0.22 & -0.30 & 0.15 & 0.09 \\
\hline \multicolumn{4}{|c|}{ Eigenvalue } & 3.01 & 2.34 & 1.90 & 1.42 & 1.33 \\
\hline \multicolumn{4}{|c|}{ Cumulative $\%$ variance explained } & $23 \%$ & $41 \%$ & $56 \%$ & $67 \%$ & $77 \%$ \\
\hline
\end{tabular}

${ }_{1}^{1}$ Edge variables were regressed against habitat amount and residuals were used in principal component analysis. This removes the effects of habitat amount that were confounded with edge effects. 
Table 3. Linear Models for Grassland Breeding Bird Abundance (2000 - 2004) in Nebraska, Kansas and Missouri. Standard Errors for Model Parameters are in Parentheses; Spatial Covariance Structures in Final Parentheses

\begin{tabular}{|c|c|c|c|}
\hline \multirow{2}{*}{ Common Name (Scientific Name) } & \multicolumn{3}{|c|}{ Cumulative $R^{2}$ by Stage } \\
\hline & LCs & $+\mathbf{C R P}$ & +Trend \\
\hline $\begin{array}{c}\text { Northern Bobwhite (Colinus virginianus) } \\
\log _{10}(\mathrm{Y}+1)^{1}=1.01+0.09(0.03) \mathrm{LC}^{* * * *}-0.05(0.04) \mathrm{LC} 2+0.07(0.07) \mathrm{LC} 5^{* * *}+1.39(0.35) \text { Area_CP1_New }{ }^{* * * *}+ \\
2.71(2.22) \mathrm{PD} \_\mathrm{CP} 1^{* * *}-0.96(0.43) \mathrm{N}^{* * * *}+1.60(1.07) \mathrm{EN}+0.86(4.23) \mathrm{EN}^{2} \text { (exponential) }\end{array}$ & 0.38 & 0.51 & 0.67 \\
\hline $\begin{array}{c}\text { Horned Lark (Eremophila alpestris) } \\
\log _{10}(\mathrm{Y}+1)=0.46-0.16(0.03) \mathrm{LC1}^{* * * *}-0.16(0.05) \mathrm{LC}^{* * * * *}-0.15(0.04) \mathrm{LC}^{* * * *}+0.06(0.05) \mathrm{LC}^{* * *}+0.05(0.04) \\
\text { Area_CP2 } 2^{* *}+9.13(2.56) \mathrm{PD}_{-} \mathrm{CP}^{* * * *}-2.34(0.84) \mathrm{N}+5.00(1.56) \mathrm{EN}+3.11(0.86) \mathrm{E}^{2 * * *}+16.36(4.98) \mathrm{E}^{2} \mathrm{~N}^{*}+29.12 \\
(10.87) \mathrm{EN}^{2}+35.68(11.32) \mathrm{N}^{3 * *} \text { (gaussian) }\end{array}$ & 0.52 & 0.60 & 0.71 \\
\hline $\begin{array}{c}\text { Grasshopper Sparrow (Ammodramus savannarum) } \\
\log _{10}(\mathrm{Y}+1)=0.93-0.08(0.03) \mathrm{LC1}^{* *}-0.13(0.04) \mathrm{LC}_{2}^{* * * *}+0.08(0.04) \mathrm{LC} 4^{* *}-0.11(0.04) \mathrm{LC} 5^{*}+0.05(0.02) \\
\text { Area_GrassCRP }\end{array}$ & 0.29 & 0.39 & 0.46 \\
\hline $\begin{array}{c}\text { Dickcissel (Spiza americana) } \\
\operatorname{sqrt}(\mathrm{Y}+0.5)=6.80+0.28(0.19) \mathrm{LC1}^{* * * *}-0.57(0.20) \mathrm{LC}^{* * * * *}+0.70(0.23) \mathrm{PC}^{* * * *}+0.43(0.10) \text { Area_GrassCRP } \\
73.50(49.15) \mathrm{PD} C \mathrm{CP} 1 \_\mathrm{New}^{* * * * *}-8.55(3.09) \mathrm{N}^{* * * *}-19.54(3.35) \mathrm{E}^{2 * * * *}+47.46(35.19) \mathrm{N}^{3}\end{array}$ & 0.35 & 0.46 & 0.66 \\
\hline $\begin{array}{c}\text { Mourning Dove (Zenaida macroura) } \\
\log _{10}(\mathrm{Y}+1)=1.61-0.14(0.02) \mathrm{LC}^{* * * *}-0.05(0.02) \mathrm{LC} 3^{* * * *}+0.05(0.02) \mathrm{LC}^{* *}+0.08(0.02) \mathrm{LC}^{* * * *}+0.02(0.01) \\
\text { Area_GrassCRP }\end{array}$ & 0.58 & 0.63 & 0.64 \\
\hline 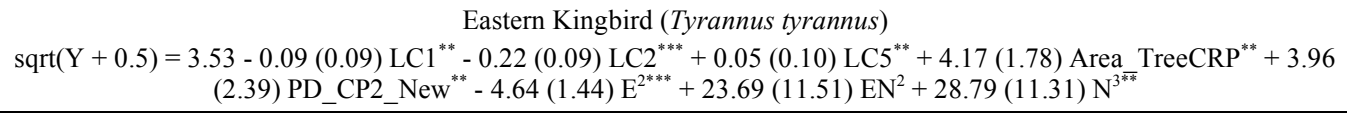 & 0.17 & 0.26 & 0.40 \\
\hline $\begin{array}{c}\text { Common Yellowthroat (Geothlypis trichas) } \\
\log _{10}(\mathrm{Y}+1)=0.58+0.02(0.02) \mathrm{LC}^{* * * *}+0.09(0.03) \mathrm{LC}^{* * * *}+0.07(0.03) \mathrm{LC}^{* *}+0.32(0.06) \text { Area_CP1 } 1^{* * * *}+3.66 \\
(0.60) \mathrm{E}^{3 * * *}+12.15(2.26) \mathrm{N}^{3 * * * *}\end{array}$ & 0.21 & 0.39 & 0.63 \\
\hline $\begin{array}{c}\text { Lark Sparrow (Chondestes grammacus) } \\
\log _{10}(\mathrm{Y}+1)=0.48-0.04(0.03) \mathrm{LC}^{* * *}-0.15(0.04) \mathrm{LC} 2^{* * * *}-0.06(0.03) \mathrm{LC}^{* *}-1.27(1.27) \mathrm{PD} \_ \text {GrassCRP_New } \\
0.21(0.25) \mathrm{E}+1.14(0.77) \mathrm{EN}-7.39(3.10) \mathrm{EN}^{2 * *}\end{array}$ & 0.48 & 0.50 & 0.54 \\
\hline $\begin{array}{c}\text { Brown-headed Cowbird (Molothrus ater) } \\
\log _{10}(\mathrm{Y}+1)=1.50+0.02(0.03) \mathrm{LC} 1^{* * * *}-0.02(0.04) \mathrm{LC} 2^{* *}-9.72(5.52) \mathrm{PD} \_ \text {AreaCP1_New }{ }^{* *}-0.41(0.38) \mathrm{E}-1.63 \\
(0.60) \mathrm{EN}-2.11(0.45) \mathrm{E}^{2 * * * *}+2.65(1.17) \mathrm{E}^{3 * *}\end{array}$ & 0.20 & 0.23 & 0.46 \\
\hline $\begin{array}{c}\text { Indigo Bunting (Passerina cyanea) } \\
\log _{10}(\mathrm{Y}+1)=0.84+0.09(0.02) \mathrm{LCl}^{* * * *}+0.27(0.04) \mathrm{LC} 2^{* * * *}+0.15(0.03) \mathrm{LC}^{* * * *}-0.07(0.03) \mathrm{LC}^{* * *}+0.97(0.51) \\
\text { Area_TreeCRP }\end{array}$ & 0.82 & 0.84 & 0.85 \\
\hline
\end{tabular}

${ }^{1} \mathrm{Y}=$ bird abundance transformed as indicated to meet assumptions of general linear models.

$P \leq 0.10 ;{ }^{* *} P \leq 0.05 ;{ }^{* * *} P \leq 0.01 ;{ }^{* * * *} P \leq 0.001$. P-values based on Type I sums of squares which preserves the order in which we added variables to the models.

study area following the protocol of Flather \& Sauer [38] as modified in Pidgeon et al. [39]. A $25-\mathrm{km}$ radius approximated the mean maximum natal dispersal distances [40] of our focal species (northern bobwhite $\approx 28.5 \mathrm{~km}$, all species average $\approx 24 \mathrm{~km}$ ); hence, these species should respond to landscape characteristics at this scale (C. H. Flather, personal communication). This size also ensured that the entire BBS route was contained within the landscape.

After careful consideration of the dominant land use types in our study area and the ecological requirements of grassland bird species, we calculated the following landscape variables for each $1,962-\mathrm{km}^{2}$ landscape: percent of the landscape comprised of open water, urban (residential land + commercial land + urban/recreational grasses), forest (deciduous + evergreen + mixed upland forest), grassland (grassland + barren transistional + shrubland), pasture-hay, row crops (row crops + small grains), and wetlands. The grassland category included NLCD land cover class 33 (barren transitional) and 51 (shrublands) because both contain some grassland cover (e.g., reclaimed strip-mined lands). Because we primarily condensed land-cover types to Level I categories (e.g., forest category does not distinguish among different forest types), accuracy was high $(\approx 80-$ $85 \%$; [41]). NLCD categories are based on the Anderson system where Level I categories are those that can be efficiently and accurately gathered at large spatial scales (e.g., nation, regions and states). Because landscape configuration may strongly influence grassland bird distributions [42], we 
also calculated 6 configuration metrics: mean patch size, patch density, and edge density for both forest and grassland.

We calculated CRP metrics representing both general and specific characteristics of CRP (each is listed and defined in Table 1). Total Area of CRP (Area_CRP) was the most general characterization of CRP which was the \% of the landscape comprised of all CRP regardless of practice. Then we calculated 3 classes of metrics to measure specific CRP characteristics. First, we calculated practice-specific metrics as the $\%$ of the $1,962-\mathrm{km}^{2}$ landscape comprised of specific practices (listed and defined in Table 1). For example, Area_CP2 was the \% of the landscape comprised of CP2 (native grass) and Area WoodyStrips was the \% of the landscape comprised of tree-based strip practices like riparian buffers. Second, we calculated configuration metrics (listed and defined in Table 1) for both total CRP and the practice-specific classifications to characterize the spatial configuration of CRP in the $1,962-\mathrm{km}^{2}$ landscapes. Third, we calculated new-CRP metrics as the \% of the $1,962-\mathrm{km}^{2}$ landscapes comprised of recently established CRP.

To calculate new-CRP metrics, we recalculated total CRP, practice-specific metrics and configuration-specific metrics except we restricted the calculation to include only those newly-planted contracts $\leq 4$ years old (initiated after 2000) that were still in an early successional stage. CP10 (existing grasses) and CP11 (existing trees) were omitted from new-CRP metrics because these practices are reenrollments of existing grass and trees, and, in the absence of disturbance, would not be early successional habitats. Because some of the older CRP habitat that we excluded may have been hayed or grazed under emergency grazing allowances, it is possible some of the CRP habitat excluded from these newly established variables were in an early successional stage. However, it is impossible to distinguish disturbed CRP from undisturbed CRP given available datasets. Thus, we calculated our newly established CRP variables in a manner that insured all CRP included in that variable was indeed early successional.

Because landscape configuration metrics (e.g., forest edge) and configuration-specific CRP metrics (e.g., patch density of total CRP) are often confounded with habitat amount [43], we regressed each configuration metric against the appropriate habitat amount, including $2^{\text {nd }}-$ and $3^{\text {rd }}$-order polynomial terms [44] if they substantially improved model fit $\left(\Delta \mathrm{AIC}_{\mathrm{C}}<2.0\right)$. We retained the residuals as adjusted configuration metrics independent of the confounding effects of habitat amount.

\section{Statistical Techniques}

To describe bird-CRP relations, we used a multi-stage regression technique where we regressed bird abundance against successive sets of potential predictor variables and retained the residuals as dependent variables for the next step $[42,45,46]$. The order of the steps reflected our priorities for analyses - (1) accounting for general landscape structure and configuration; (2) modeling effects of CRP metrics; (3) accounting for spatial autocorrelation in model residuals.

The first stage involved fitting a landscape model. We accounted for the effects of general landscape composition and configuration before including CRP variables because
CRP may be confounded with general landscape characteristics. Because many of our landscape metrics were correlated, we conducted a principal component analysis. Landscape variables were transformed as needed to achieve normality and linearize relationships among variables. We retained components with eigenvalues $>1$, leaving us with 5 landscape components (LC1 - LC5; Table 2). Using PCA eliminated effects of multi-collinearity in this stage because principal components are by definition orthogonal. We selected the best-fitting combination of landscape components using $\mathrm{AIC}_{\mathrm{c}}$ [47].

In the second stage, we used the residuals from the first stage as dependent variables (representing abundance adjusted for landscape characteristics). Many of the CRP metrics represented finer subsets of other metrics (e.g., area of grass CRP is a subset of area of all CRP) and so were highly correlated. But, because we wanted to evaluate these specific characteristics of CRP (rather than simply control for their effects), we could not use principal components. To avoid multi-collinearity problems, we constructed a set of candidate models including 1- and 2-variable models but omitted those that contained multiple area-based metrics (which would be correlated with each other) or multiple configuration metrics (also correlated). Area-based metrics were not correlated with configuration metrics because configuration metrics were corrected for habitat area (see above). This eliminated concerns of collinearity at this stage. We selected the CRP model with the lowest $\mathrm{AIC}_{\mathrm{c}}$.

As a final stage, we accounted for spatial autocorrelation (when observations from routes that are close to each other are more similar to each other than to more distant routes) because spatial autocorrelation violates the independenterrors assumption of regression and can lead to biased estimates of the effects of explanatory variables [48]. However, spatial models can also cause bias by de-emphasizing the importance of broad-scale variables [49]. Because we were explicitly investigating broad-scale relations, we avoided potential bias by conducting the spatial part of our analysis last, after landscape and CRP variable were already included.

We inspected the residuals from each regression model for spatial autocorrelation by calculating robust estimates of the semivariogram. We then used SAS Proc Mixed to test spatial covariance structures (exponential, Gaussian, spherical) using starting values derived from the semivariograms. We used - $2 \log$ likelihood test $(\alpha=0.05)$ to determine if a spatial covariance term was required $[50,51]$. Because tests for autocorrelation assume stationarity [52], we first removed any remaining spatial trends from the second-stage residuals by fitting the best regression including some combination of third-order polynomial terms of the centered site coordinates $\left(E, N, E^{2}, N^{2}, E N, E^{2} N, E^{2}, E^{3}, N^{3}\right.$, where $E=$ easting and $\mathrm{N}=$ northing $[51,53]$. Centering the coordinates reduced the potential for collinearity at this stage [54]. Thus, our final models contain parameter estimates that are not biased by residual spatial autocorrelation in bird metrics.

To assess the strength of bird-CRP relations, we conducted simple sensitivity analyses for each CRP metric retained in a final model. First, we parameterized the model with mean values for each variable in the model. Then, we increased (i.e., perturbed) the CRP metric by $10 \%$ of the 
mean value and calculated the \% change in the response variable (bird abundance).

\section{RESULTS}

\section{Landscape Characteristics}

We retained 5 principal components that explained a total of $77 \%$ of the variation in the original 13 landscape variables (Table 2). These landscape components explained an average of $42 \%$ of the variation (model $R^{2}$ ) in grassland bird abundance, ranging from $17 \%$ for eastern kingbird to $82 \%$ for indigo bunting (Table 3).

\section{Bird-CRP Relations}

Within our study area, an average of $2.9 \%$ of each $1,962-$ $\mathrm{km}^{2}$ landscape was comprised of CRP, but this ranged from
$0.0 \%$ to just over $15.0 \%$ (Table 1 ). The majority of the CRP land $(\approx 90 \%)$ was enrolled in one of many available grassbased practices. Within this region, nativegrasses (CP2) were over 3 times as prevalent as exotic grasses (CP1). Sizes of CRP patches averaged 11.40 ha, but ranged as large as 114.6 ha.

All of the species we studied were related to at least one characteristic of CRP habitat (Tables 3 and 4). CRP metrics accounted for an average of $8 \%$ additional variation (model $R^{2}$ ) in grassland bird abundance beyond that explained by general landscape characteristics (Table 3), and this ranged from $2 \%$ (lark sparrow and indigo bunting) to $18 \%$ (common yellowthroat). Specific CRP metrics always fit better than did the generic CRP metric (total \% of landscape in CRP) which combined all practices into one category. On average, the difference in $\mathrm{AIC}_{\mathrm{c}}$ between the generic CRP metric and the best-fitting model was 6.24 (Fig. 1), indicating that there

Table 4. Sensitivity Analysis of Significant CRP Responses by grassland birds in Kansas, Nebraska and Missouri (2000 - 2004)

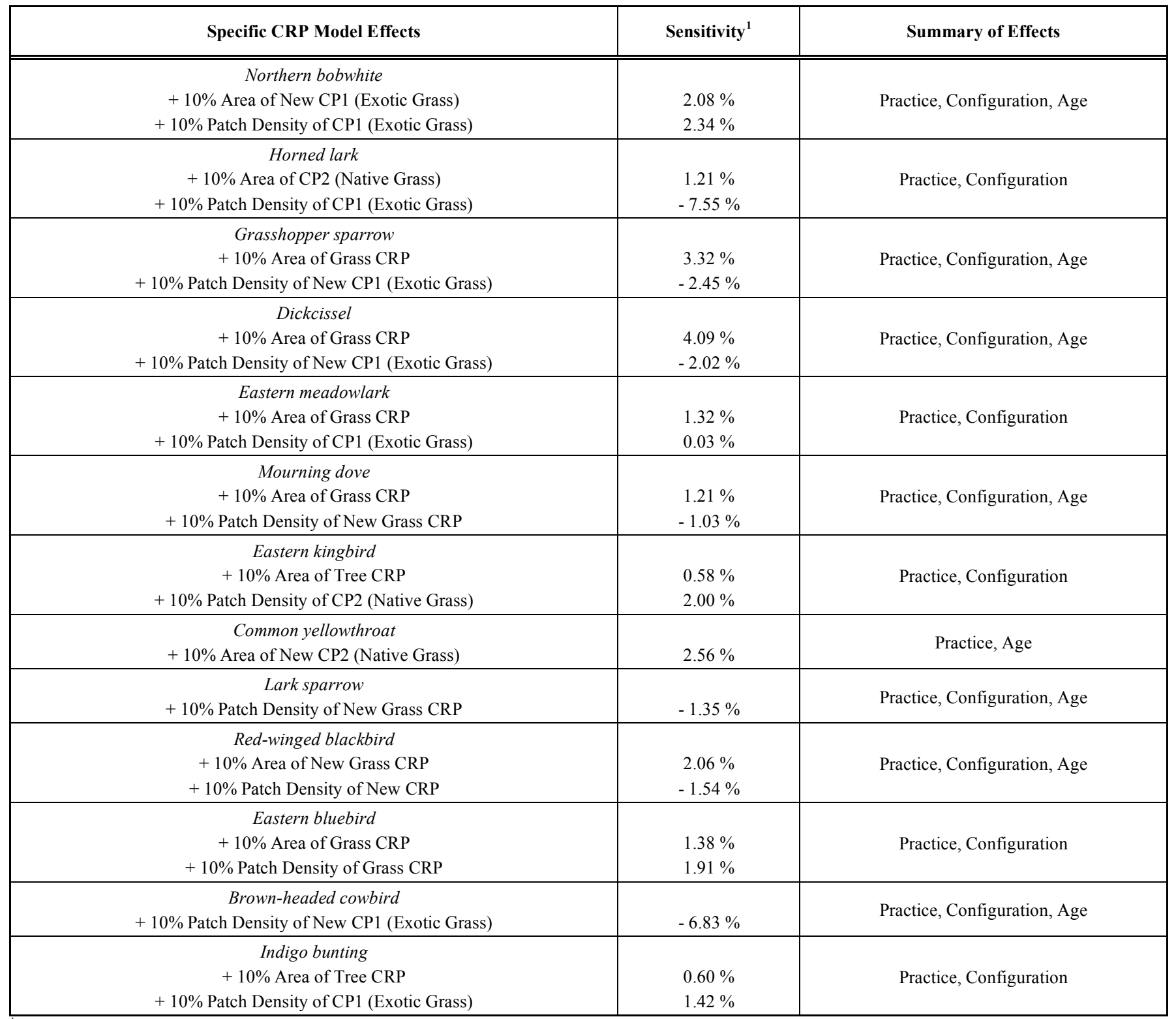

${ }^{1}$ Sensitivity analyses measured \% change in bird abundance related to $+10 \%$ increases in the listed CRP variable. Baseline value derived from the model (Table 3) parameterized with the mean values (from Table 1) for each variable. 


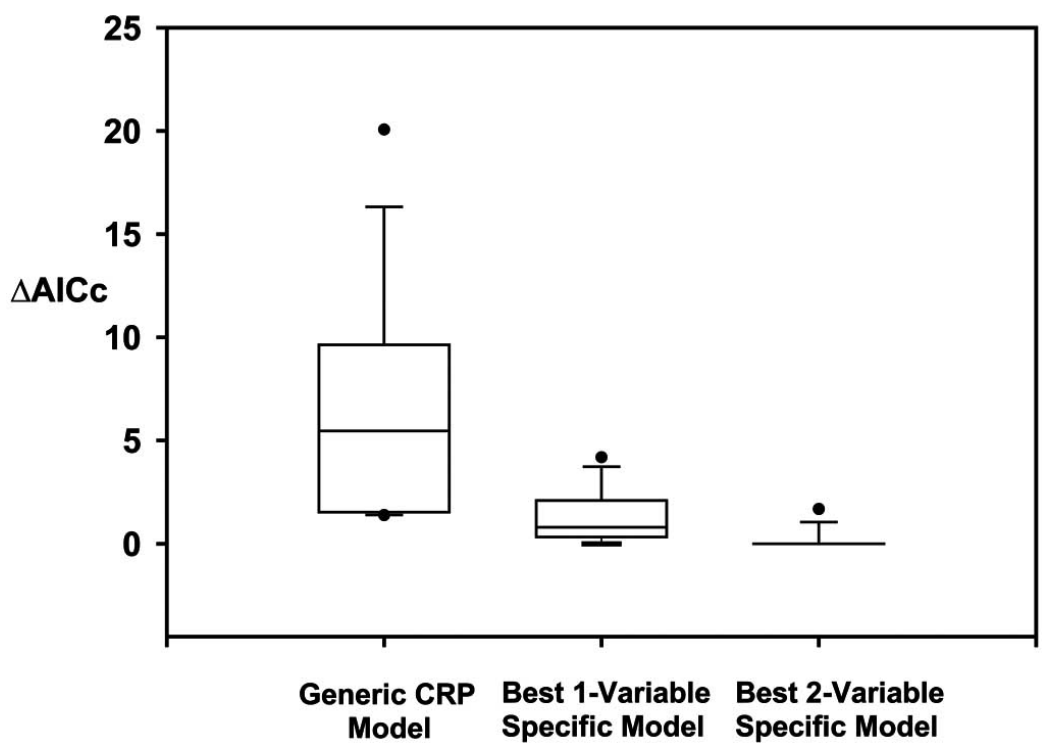

Fig. (1). Box and whiskers plot comparing model fit $\left(\Delta \mathrm{AIC}_{\mathrm{c}}\right)$ for models using only a generic classification of $\mathrm{CRP}$, models containing 1 specific CRP metric, and models containing 2 specific CRP metrics. $\triangle \mathrm{AIC}_{\mathrm{c}}=0.0$ for the best fitting model for a species.

was considerably more support for models using specific CRP metrics.

Practice-specific metrics were important for all species. Grasshopper sparrow, dickcissel, eastern meadowlark, mourning dove, red-winged blackbird, and eastern bluebird were positively related to grass CRP practices, whereas lark sparrow was negatively related to grass practices (Tables $\mathbf{3}$ and 4). Eastern kingbird and indigo bunting were positively associated with tree-based practices. More refined distinctions among practice types were also important. Characteristics of CP1 (exotic grasses) were positively related with abundance of 3 species (northern bobwhite, eastern meadowlark, and indigo bunting), but negatively related to abundance of horned lark, grasshopper sparrow, dickcissel and brown-headed cowbird.

Configuration metrics were related to 12 of 13 species. Northern bobwhite, eastern meadowlark, eastern kingbird, eastern bluebird and indigo bunting were positively related to CRP patch density metrics, indicating preference for landscape where CRP habitat was distributed in more, but potentially smaller, patches (Tables 3 and 4). Conversely, horned lark, grasshopper sparrow, dickcissel, mourning dove, lark sparrow, red-winged blackbird, and brown-headed cowbird were negatively related to patch density, indicating a potential affinity for more clumped arrangements of CRP habitat. Common yellowthroat was the only species not related to CRP configuration.

Abundance of 8 species were related to metrics of recently established CRP habitat where succession had not yet progressed beyond an early seral stage $(\leq 4$ years since establishment). Northern bobwhite and common yellowthroat were more abundant in landscapes containing more new CRP. Horned lark, grasshopper sparrow, dickcissel, mourning dove, and brown-headed cowbird were negatively related to patch density of new CRP habitat. Red-winged blackbirds were positively related to the area of new grass CRP, but negatively associated with the patch density of new CRP. Thus, red-winged blackbirds may be exhibiting a configuration effect rather than a true negative response to new CRP.

\section{Spatial Autocorrelation}

After including variables representing landscape characteristics and CRP habitat, polynomial terms of the route coordinates explained, on average, an additional $11 \%$ of the variation (model $R^{2}$ ) in grassland bird abundance, ranging from $1 \%$ (mourning dove, indigo bunting) - 24\% (common yellowthroat). Final models included an average of 2.9 trend variables (range 1 - 6).

Based on - 2 log likelihood tests, residuals from models for northern bobwhite, horned lark, eastern meadowlark, redwinged blackbird and indigo bunting exhibited substantial spatial autocorrelation. We accounted for this by including a spatial covariance term for these species.

\section{Final Models and Sensitivity Analysis}

The final model for each species contained landscape components, CRP habitat metrics, and broad-scale trend terms that were selected at each stage of our analysis. Because we included spatial covariance structures when needed, these final models have coefficients and standard errors that were unbiased by residual spatial autocorrelation. Landscape components, CRP, and spatial trends explained an average $61 \%$ of the variation in bird abundance (model $R^{2}$ ), ranging from $40 \%$ for eastern kingbird to $85 \%$ for indigo bunting (Table $\mathbf{3}$ ).

Sensitivity analysis indicated that $10 \%$ increases in CRP habitat metrics were associated with concomitant changes of $<10 \%$ in bird abundance. For metrics related to habitat amount, these concomitant changes ranged from $0.6 \%$ (eastern kingbird) to $4.1 \%$ (dickcissel). For patch density metrics (residualized), the concomitant changes ranged from $2.6 \%$ (common yellowthroat) to $7.6 \%$ (horned lark). Sensitivity of configuration metrics was not consistently higher or lower than sensitivity of CRP habitat amount variables $(t=$ $-0.68, \mathrm{P}=0.515)$. Neither habitat amount nor configuration 
were more important than the other for grassland birds as a group.

\section{DISCUSSION}

Although all 13 grassland birds were related to CRP habitat, individual species responded to different combinations of CRP attributes and in a variety of directions (i.e., some negatively and some positively), likely because of differences in niche requirements. Discussion of each species-specific account, while valuable, would be lengthy and distract from our purpose of evaluating characteristics of CRP. We first discuss the overall implications of our analyses in relation to pre-existing landscape conditions. Second, we discuss bird-CRP relations in the framework of the three ecological characteristics we initially delineated: practice-specific relations, configuration relations, and relations with newly established (early successional) CRP habitat.

\section{Landscape Characteristics}

If CRP habitat was confounded with pre-existing landscape conditions in our study region [18], testing for birdCRP relations without first accounting for landscape effects could have led to detection of spurious bird-CRP relations and inappropriate conclusions about proper management of CRP for grassland birds. In Illinois, for example, CRP enrollment was higher in landscapes that were relatively more fragmented (i.e., smaller patch sizes, more edge) and contained more pre-CRP grassland than the overall landscape [8]. However, a strength of our approach is that we accounted for pre-existing landscape characteristics in our first stage of analysis before modeling CRP.

We are confident that our analysis accounted for major relations between birds and pre-existing landscape conditions for several reasons. First, we used datasets that represented an appropriate temporal sequence - landscape data from circa 1992 (NLCD) and CRP data from circa 2004 (CLU data). Second, bird variables were related to landscape components in ways that were consistent with known habitat- and landscape-relations of these species. For example, LC1 represented a fragmentation gradient and species with well-documented affinity for edges (e.g., northern bobwhite, common yellowthroat and indigo bunting) were positively associated with LC1. Conversely, area sensitive species including grasshopper sparrow and horned lark were negatively related to $\mathrm{LC} 1$. Consistency with known ecological relations provides added confidence in our bird-landscape models, and hence in our confidence that we adequately accounted for pre-existing landscape conditions.

\section{Bird-CRP Relations}

\section{General Implications}

Using the spatially-explicit CLU database allowed us to calculate CRP habitat metrics that were practice-specific and contained relevant information about habitat configuration and age. Grassland birds responded to CRP habitat in complex ways that were not adequately captured by a single, generic classification of CRP habitat (which is typical of many large scale assessments). Models including total CRP had little support compared to models containing more specific CRP habitat metrics (Fig. 1). Collapsing all the different cover types that comprise set-aside programs like the CRP and agri-environment schemes into a single habitat category likely obscures true relations between set-aside habitat and wildlife. Our analyses suggest more habitat- and configuration-specific metrics could substantially improve our ability to evaluate government-subsidized set-aside programs.

\section{Practice-Specific Relations}

Some practice specific variables broadly delineated CRP habitat simply into grass- and tree-based practices, and even this coarse resolution proved useful in identifying bird-CRP relations. Several grassland species were positively related to the area of grass CRP habitat in the surrounding landscape. Other studies have documented associations with or positive reproductive benefits from CRP habitat for grassland breeding birds including grasshopper sparrow [55], dickcissel [56], eastern meadowlark [23], and mourning dove [57]. Conversely, area of the landscape in tree-based practices was related to eastern kingbird and indigo bunting - edge denizens that use woody structure for foraging, perching and nesting. Our results highlight the importance of considering specific characteristics of CRP habitats (such as practice type) when evaluating the program's effect on wildlife. In areas like the Southeastern US where tree practices are more common [22], CRP may benefit shrub or forest species rather than grassland species, but there is little research about CRP benefits for forest birds.

We also constructed CRP habitat metrics that distinguished between different grass practices - CP1 (introduced grass) vs. CP2 (native grass) - and the area metrics for these practices were important for two species. Abundance of common yellowthroat and horned lark was related to the amount of native grass (CP2) practice in the surrounding landscape. Although most documented responses of horned lark to CRP have been negative [56, 58,], Johnson \& Schwarz [59] documented horned lark preference for native grass CRP.

Generally, native grass plantings (like CP2 plantings) provide a more open and diverse plant community interspersed with bare ground compared with introduced grasses (like CP1). This open structure provides access for ground nesting and ground foraging birds like grasshopper sparrow [55, 60] and northern bobwhite [29]. In contrast to our expectations, neither was positively associated with CP1 (even though CP2 was dominant in the landscape). In the US, composition of $\mathrm{CP} 1$ and $\mathrm{CP} 2$ practices varies because practice standards (e.g., which species can be planted) vary from state to state. For example, Missouri CP2 fields are often comprised of monotypic stands of switchgrass (Panicum virgatum) that are actually more dense (hence less suitable) than nearby CP1 fields [23]. Moreover, specific species composition of CRP planting mixtures has changed over time. In 1997, a new environmental benefits index (EBI) that emphasized diverse planting mixtures was adopted for ranking CRP bid offers. Thus, CP1 and CP2 plantings established after 1997 likely exhibit greater structural and floristic diversity than those studied by McCoy et al. [23] and undesirable plant species (e.g., fescue) have been 
eliminated from eligibility in many states. This underscores how temporal and geographical differences in practice standards can thwart broad assessments of set-aside programs [6, 61]. Region-specific information about bird-CRP relations should be used, when available, for management decisions.

The consensus of these results is that some species were positively related to native grasses while others were positively related to introduced grasses. Most practice-specific relations, however, were observed in CRP metrics that also contained information about configuration and/or new CRP habitat, such as patch density of CP1 (introduced grass), indicating that relations to CRP practices can be complex (Table 4). We discuss this complexity below.

\section{Configuration Effects}

Only red-winged blackbird was related to a CRP habitat metric that represented a simple configuration effect (negatively related to patch density of total CRP; Table 4), but numerous species were related to configuration of a particular practice or to configuration of recently established CRP habitat. Overall, edge-associated species (e.g., northern bobwhite, indigo bunting) were positively associated with configuration metrics, but area-sensitive species such as grasshopper sparrow $[57,62]$ were negatively related (Tables 3 and 4). Because we used residualized configuration metrics, confounding effects of CRP habitat area were removed so that these variables represented independent effects of configuration over and above effects associated with habitat amount [46]. For example, grasshopper sparrow and dickcissel were both positively related to area of grass CRP, but negatively related to patch density of CP1 (introduced grass). This indicates a positive effect of habitat amount and an additional negative effect of habitat fragmentation. Similarly, positive habitat amount effects and negative configuration effects were observed for mourning dove, red-winged blackbird, brown-headed cowbird. In contrast, models for some edge species like eastern bluebird contained positive effects of both habitat amount and configuration.

CRP has the potential to benefit both edge and areasensitive species because the program contains whole field practices (e.g., large blocks of grass) and practices that create grassland edge (e.g., field borders). Although habitat management and conservation often target area-sensitive species that require large, unbroken tracts of habitat $[13,57$, 62 but see 63], many edge species are declining in North America as well $[9,14]$. Thus, addition of numerous small patches of habitat often provided by the CRP could benefit many declining, edge-related species. A comprehensive approach to grassland bird conservation should strive to increase both the number of large (for area-sensitive species) and small (for edge species) set-aside patches in a landscape mosaic. Future implementation of the CRP could reflect this by targeting edge species in some landscapes and areasensitive species in others; or by simultaneously providing block and strip habitat using different practices.

\section{Recently Established CRP Habitat}

Red-winged blackbird and northern bobwhite were positively related to the amount of recently established CRP habitat. Recently established CRP is important for northern bobwhite because, in the absence of periodic disturbance (e.g., disking, burning, mowing) that mimics historical disturbance regimes, CRP habitat may become less suitable for northern bobwhite over time [29, 30, 33]. Thus, requiring mid-contract management (periodic disking or burning) as part of the landowner contract would help inhibit ecological succession and retain benefits to northern bobwhite and perhaps other birds that use early successional habitats. Some conservation practices recently added to the CRP do require such activities (i.e., CP33 Habitat Buffers for Upland Birds). We caution that 5 species were negatively related to patch density of recently established CRP habitat. It is difficult to ascertain whether these relations are driven by early successional habitat per se or by the configuration of these habitats, or another correlated factor. It is clear, however, that periodic disturbance to grass CRP habitat would likely benefit some species, while others would benefit from older, undisturbed CRP habitat (just like with configuration). Again, a comprehensive approach to grassland bird conservation might intentionally retain a mosaic of undisturbed (late successional) and disturbed (early successional) setaside habitat in the landscape.

\section{CONCLUSIONS AND GENERAL MANAGEMENT RECOMMENDATIONS}

Our findings suggest that CRP habitat is generally related to higher abundance of many grassland birds. Thus, increasing landowners' participation in the Conservation Reserve Program may benefit populations of grassland birds and possibly help slow or reverse negative population trends. There is great potential (currently largely untapped) to target establishment and management of CRP habitats to particular species [64]. For example, the Northern Bobwhite Conservation Initiative - a regional management plan to restore northern bobwhite populations to 1980 levels [65, 66] - has targeted a specific CRP practice (CP33 Habitat Buffers for Upland Birds) with a configuration to which bobwhite will respond (small, linear habitat patches with high edge density and interspersion) and mid-contract management appropriate for northern bobwhite. However, comprehensive management for entire guilds of grassland and/or edge species need to include a variety of practice types in a landscape mosaic that contains both large and small tracts of CRP habitat (to address needs of both area-sensitive and edge species) across a spectrum of successional stages. Because of the numerous practice types (Appendix A) available, the CRP has great potential as part of multi-species, regional management efforts.

Our results suggest that even small amounts of set-aside (CRP habitat comprised $2-3 \%$ of a typical landscape in our study) can have substantial impacts on regional bird populations. Although sensitivity analysis indicated that $10 \%$ changes in the CRP habitat variables (either amount or configuration) were associated with relatively small changes in bird abundance $(<10 \%)$, this should be put into proper perspective. For example, converting just an additional $1 \%$ of a landscape to grass CRP (a very achievable conservation goal) represents a $40 \%$ increase from the current average $(2.55$ to $3.55 \%)$, and this would translate into a $17 \%$ increase in dickcissel abundance based on our models. Plus, many landscapes in our study contained amounts of CRP (up to $15 \%$ of some landscapes in our study; Table 1) greater than 
the $>3 \%$ threshold identified for population effects in other regions $[55,67]$. It should not be surprising that even small land cover conversions (e.g., $1 \%$ of the landscape) could impact regional populations when one considers that these changes are occurring in landscapes where $\approx 99 \%$ of the original grassland habitat no longer remains [13].

Our results do not suggest, however, that set-aside programs like the CRP are a panacea for grassland birds. The amount of variation in bird abundance explained by CRP metrics was small compared to the amount explained by landscape components. To be most effective, set-aside programs should be administered to complement other attributes of landscape composition and configuration (e.g., forest cover, connectivity). Set-aside programs may not produce maximum wildlife benefits when administered in isolation rather than as part of a comprehensive conservation strategy $[27,68]$.

The CLU database, and hence our current analysis, was limited to only a 3 -state area. Thus, we cannot make any nationwide conclusions about CRP effects, and our results should not be applied beyond the states of Kansas, Missouri and Nebraska. Other relations might be expected in other physiographic regions with differing landscape contexts [61]. Our results underscore the need for continued development of broad-scale (i.e., national or continental), spatiallyexplicit data; not only for describing CRP habitat, but also for describing the complete spectrum of climate, environmental, socio-economic and land cover variables. Ideally, these datasets should be updated over time so that change trajectories can be modeled $[6,21]$. Only with such complete data will unequivoal answers about the effects of regional landscape modifications like the Conservation Reserve Program be possible.
ABBREVIATIONS
BBS $=$ Breeding Bird Survey
AICc $=$ Aikaike's Information Criterion (small-sample version)
$\mathrm{CLU}=$ Common Land Unit database
$\mathrm{CRP}=$ Conservation Reserve Program
$\mathrm{CP}=$ Conservation practice
$\mathrm{LC}=$ Landscape component derived from PCA
PCA = Principal components analysis
USDA = United States Department of Agriculture

\section{ACKNOWLEDGEMENTS}

Discussions with C. H. Flather, K. J. Gutzwiller, S. Hyberg, and R. Iovanna helped us refine our modeling techniques. Several anonymous reviews improved the manuscript. R. Hamrick, M. Smith, and our colleagues at Mississippi State provided logistical support and vital interaction. Our work was funded by the USDA Farm Service Agency.

\section{Appendix}

Appendix A. List of Available Conservation Practices in the Conservation Reserve Program from 1986 - 2004

\begin{tabular}{|c|c|c|c|}
\hline Code & Description & Code & Description \\
\hline $\mathrm{CP} 1$ & Introduced Grasses & $\mathrm{CP} 16,16 \mathrm{~A}$ & Shelterbelts \\
\hline $\mathrm{CP} 2$ & Native Grasses & $\mathrm{CP} 17,17 \mathrm{~A}$ & Living Snow Fences \\
\hline $\mathrm{CP} 3$ & Softwood Tree Planting & $\mathrm{CP} 18,18 \mathrm{~B}$ & Salinity Reducing Vegetation \\
\hline CP3A & Hardwood Tree Planting & CP18A, 18C & Salt Tolerant Vegetation \\
\hline $\mathrm{CP} 4,4 \mathrm{D}$ & Wildlife Habitat & CP19 & Alley Cropping \\
\hline $\mathrm{CP} 4 \mathrm{~A}, 4 \mathrm{~B}$ & Wildlife Habitat Corridor & $\mathrm{CP} 20$ & Alternative Perennials \\
\hline $\mathrm{CP} 5,5 \mathrm{~A}$ & Field Windbreaks & $\mathrm{CP} 21$ & Filter Strips \\
\hline CP6 & Diversions & $\mathrm{CP} 22$ & Riparian Buffers \\
\hline $\mathrm{CP} 7$ & Erosion Control Structures & $\mathrm{CP} 23,23 \mathrm{~A}$ & Wetland Restoration \\
\hline $\mathrm{CP} 8,8 \mathrm{~A}$ & Grass Waterways & $\mathrm{CP} 24$ & Cross Wind Trap Strips \\
\hline CP9 & Wildlife Water & $\mathrm{CP} 25$ & Rare and Declining Habitat \\
\hline CP10 & Established Grass & CP26 & Sediment Retention Structures \\
\hline CP11 & Established Trees & $\mathrm{CP} 27$ & Farmable Wetlands - Wetland \\
\hline $\mathrm{CP} 12$ & Wildlife Food Plot & $\mathrm{CP} 28$ & Farmable Wetlands - Upland Buffer \\
\hline CP13A, 13C & Filter Strips - Grass & CP29 & Marginal Pasture - Wildlife Buffer \\
\hline CP13B, 13D & Filter Strips - Trees & CP30 & Marginal Pasture - Wetland Buffer \\
\hline CP14 & Wetland Trees & CP31 & Bottomland Hardwood Trees \\
\hline $\mathrm{CP} 15,15 \mathrm{~A}$ & Contour Grass Strips & $\mathrm{CP} 32$ & Expired Hardwood Tree Contracts \\
\hline $\mathrm{CP} 15 \mathrm{~B}$ & Contour Grass Terrace & CP33 & Upland Bird Habitat Buffers \\
\hline
\end{tabular}




\section{REFERENCES}

[1] Hohman WL, Halloum DJ, Eds. A comprehensive review of farm bill contributions to wildlife conservation 1985-2000. Tech Rep, USDA/NRCS/WHMI-2000, 2000.

[2] Haufler JB, Ed. Fish and wildlife benefits of farm bill conservation programs: 2000-2005 update, The Wildlife Society, Technical Reviews 05-2, Bethesda Maryland, USA 2005.

[3] Van Buskirk J, Willi Y. Meta-analysis of farmland biodiversity within set-aside land: reply to Kleijn and Baldi. Conserv Biol 2005; 19: 967-8.

[4] Kleijn D, Baldi, A. Effects of set-aside land on farmland biodiversity: comments on van Buskirk and Willi. Conserv Biol 2005; 19: 963-6.

[5] Van Buskirk J, Willi Y. Enhancement of farmland biodiversity within set-aside land. Conserv Biol 2004; 18: 987-94.

[6] Kleijn D, Baquero RA, Clough Y, et al. Mixed biodiversity benefits of agri-environment schemes implemented in contrasting European countries. Ecol Lett 2006; 9: 243-54.

[7] U. S. Department of Agriculture. Conservation reserve program overview. United States department of agriculture, Farm Service Agency Technical Publication, Washington, D. C. 2005.

[8] Weber WL, Roseberry JL, Woolf A. Influence of the Conservation Reserve Program on landscape structure and potential upland wildlife habitat. Wildl Soc Bull 2002; 30: 888-98.

[9] Sauer JR, Hines JE, Fallon J. The north american breeding bird survey, results and analysis 1966-2005, version 6.2.2006. USGS Pautuxent Wildlife Research Center, Laurel, Maryland. available from http://www.mbr-pwrc.usgs.gov/bbs/ (last accessed January 2007).

[10] Brady SJ, Flather CH. Agricultural land use patterns and grassland nesting birds. Gibier Faune Sauvage Game Wildl 1998a; 15: 77584

[11] Brady SJ, Flather CH. Range-wide patterns of northern bobwhite: landuse patterns and population trends. Gibier Faune Sauvage Game Wildl 1998b; 15: 413-31.

[12] Vickery PD, Herkert JR. Recent advances in grassland bird research: where do we go from here? Auk 2001; 118: 11-5.

[13] Brennan LA, Kuvlesky WP. North American grassland birds: an unfolding conservation crisis? J Wildl Manage 2005; 69:1-13.

[14] Valiela I, Martinetto P. Changes in bird abundance in eastern North America: urban sprawl and global footprint? Bio Sci 2007; 57: 36070 .

[15] Roseberry JL, Sudkamp SD. Assessing the suitability of landscapes for northern bobwhite. J Wildl Manage 1998; 62: 895-902.

[16] Brennan LA. Northern bobwhite (Colinus virginianus). In: Poole A, Gill F, Eds. The birds of North America. The Birds of North America, Inc.: Philadelphia, Pennsylvania 1999.

[17] Ryan MR. Impact of the conservation reserve program on wildlife conservation in the midwest. In: Hohman W, Halloum DJ, Eds. A comprehensive review of farm bill contributions to wildlife conservation 1985-2000. USDA/NRCS/WHMI-2000, 2000.

[18] Kleijn D, Sutherland WJ. How effective are European agrienvironment schemes in conserving and promoting biodiversity? J Appl Ecol 2003; 40: 947-69. http://www.bioone.org/perlserv/ ?request $=$ link-resolver\&cite_doi $=1461-023 \mathrm{X} \% 282006 \% 29009 \%$ 5B0243\%3AMBBOAS\%5D2.0.CO\%3B2\&id=I0003-0082-3556-11-KLEIJN1

[19] Murphy MT. Avian population trends within the evolving agricultural landscape of eastern and central United States. Auk 2003; 120: 20-34

[20] Veech JA. A comparison of landscape occupied by increasing and decreasing populations of grassland birds. Conserv Biol 2006; 20: $422-1432$

[21] Guidice JH, Haroldson KJ. Using regional wildlife surveys to assess the CRP: scale and data-quality issues. J Field Ornithol 2007; 78: 140-51

[22] Burger LW. Wildlife responses to the conservation reserve program in the southeast. In: Hohman W, Halloum DJ, Eds. A comprehensive review of farm bill contributions to wildlife conservation 1985-2000. USDA/NRCS/WHMI-2000, 2000.

[23] McCoy TD, Ryan MR, Burger LW. Grassland bird conservation: CP1 vs. CP2 plantings in conservation reserve program fields in Missouri. Am Midl Nat 2001; 145: 1-17.

[24] Henderson IG, Cooper J, Fuller RJ, et al. The relative abundance of birds on set-aside and neighbouring fields in summer. J Appl Ecol 2000; 37: 335-47.
[25] Bracken F, Bolger T. Effects of set-aside management on birds breeding in lowland Ireland. Agric Ecosyst Environ 2006; 117: $178-84$

[26] White CG, Schweitzer SH, Moore CT, et al. Evaluation of the landscape surrounding northern bobwhite nest sites: a multi-scale analysis. J Wildl Manage 2005; 69: 1528-37.

[27] Whittingham MJ. Will agri-environment schemes deliver substantial biodiversity gain, and if not why not? J Appl Ecol 2007; 44: $1-5$.

[28] Roseberry JL, David LM. The conservation reserve program and northern bobwhite population trends in Illinois. Trans Illinois Acad Sci 1994; 87: 61-70.

[29] Burger LW, Kurzejeski EW, Dailey V, et al. Structural characteristics of vegetation on CRP fields in northern Missouri and their suitability as bobwhite habitat. Trans North Am Wildl Nat Resources Conf 1990; 55: 74-83.

[30] McCoy TD, Kurzejeski EW, Burger LW, et al. Effects of conservation practice, mowing, and temporal changes on vegetation structure on conservation reserve program fields in northern Missouri. Wildl Soc Bull 2001; 29: 979-87.

[31] Gill DE, Blank P, Parks J, et al. Plants and breeding bird response on a managed conservation reserve program grassland in Maryland. Wildl Soc Bull 2006; 43: 944-56.

[32] Greenfield KC, Burger LW, Chamberlain MJ, et al. Vegetation management practices on conservation reserve program fields to improve northern bobwhite habitat quality. Wildl Soc Bull 2002; 30: 527-38.

[33] Greenfield KC, Chamberlain MJ, Burger LW, et al. Effects of burning and disking conservation reserve program fields to improve habitat quality for northern bobwhite (Colinus virginianus). Am Midl Nat 2003; 149: 344-53.

[34] Robbins CS, Bystrack D, Geissler RH. The breeding bird survey: its first fifteen years, 1965-1979. Resource publication 157. U.S. Fish and Wildlife Service, Washington, D.C. 1986.

[35] Robbins CS, Van Velzen WT. The breeding bird survey, 1966 special scientific report wildlife number 102. U.S. Fish and Wildlife Service, Washington, D.C. 1967.

[36] O'Connor RJ, Dunn E, Johnson DH, et al. A programmatic review of the North American breeding bird survey: report of a peer review Panel. USGS Patuxent Wildlife Research Center, Laurel, Maryland 2000. Available via http://www.pwrc.usgs.gov/bbs/ bbsreview/ (Accessed January 2007).

[37] Vickery PD, Tubaro PL, Cardosa JM, et al. Conservation of grassland birds in the western hemisphere. Stud Avian Biol 1999; 19: 2-26.

[38] Flather C, Sauer JR. Using landscape ecology to test hypotheses about large-scale abundance patterns in migratory birds. Ecology 1996; 77: 28-35

[39] Pidgeon AM, Radeloff VC, Flather $\mathrm{CH}$, et al. Associations of forest bird species richness with housing and landscape patterns across the USA. Ecol Appl 2007; 17: 1989-2010.

[40] Sutherland GD, Harestad AS, Price K, et al. Scaling of natal dispersal distances in terrestrial birds and mammals. Conserv Ecol 2000; 4: 16. Available from http://www.consecol.org/vol4/iss1/ art16 (last accessed January 2007).

[41] Wickham JD, Stehman SV, Smith JH, et al. Thematic accuracy of the 1992 national land-cover data for the western United States. Remote Sens Environ 2004; 91: 452-68

[42] Hamer T, Flather C, Noon B. Factors associated with grassland bird species richness: the relative roles of grassland area, landscape structure, and prey. Landscape Ecol 2006; 21: 569-83.

[43] Fahrig L. Effects of habitat fragmentation on biodiversity. Ann Rev Ecol Syst 2006; 34: 487-515.

[44] Villard M-A, Trzcinski MK, Merriam G. Fragmentation effects on forest birds: relative influence of woodland cover and configuration on landscape occupancy. Conserv Biol 1999; 134: 774-83.

[45] Morrison ML, Marcot BG, Mannan RW. Wildlife-habitat relationships: concepts and applications. University of Wisconsin Press: Madison Wisconsin 1998

[46] Riffell SK, Keas BE, Burton TM. Birds in great lakes coastal wet meadows: is landscape context important? Landscape Ecol 2003; 18: 95-111.

[47] Burnham KP, Anderson DR. Model selection and multimodel inference: a practical information-theoretic approach. SpringerVerlag: New York 2002 
[48] Dorman CF. Effects of incorporating spatial autocorrelation into the analysis of species distribution data. Global Ecol Biogeogr 2007; 16: 129-38

[49] Diniz-Filho JAF, Bini LM, Hawkins BA. Spatial autocorrelation and red herrings in geographical ecology. Global Ecol Biogeogr 2003; 12: 53-64.

[50] Littell RC, Milliken GA, Stroup WW, et al. SAS for mixed models. SAS Institute, Inc: Cary, North Carolina 2006.

[51] Gutzwiller KJ, Barrow WC. Desert bird associations with broadscale boundary length: applications in avian conservation. J Appl Ecol 2008; 45: 873-82.

[52] Fortin MJ, Dale M. Spatial analysis: a guide for ecologists. Cambridge University Press: Cambridge 2005.

[53] Buckland ST, Elston DA. Empirical models for the spatial distribution of wildlife. J Appl Ecol 1993, 30: 478-95.

[54] Neter J, Wasserman W, Kutner MH. Applied linear regression models. Irwin Press: Homewood, Illinois 1989.

[55] Herkert JR. The influence of the CRP on grasshopper sparrow population trends in the mid-continental United States. Wildl Soc Bull 1998; 26: 227-31.

[56] Ryan MR, Burger LW, Kurzejeski EW. The impact of CRP on avian wildlife: a review. J Prod Agric 1998; 11: 62-6.

[57] Johnson DH, Igl LD. Area requirements of grassland birds: a regional perspective. Auk 2001, 118: 24-34.

[58] Best LB, Campa H, Kemp KE, et al. Bird abundance and nesting in CRP fields and cropland in the midwest: a regional approach. Wildl Soc Bull 1997; 52: 864-77.

[59] Johnson DH, Schwartz MD. The conservation reserve program: habitat for grassland birds. Great Plains Res 1993; 3: 273-95.
[60] Vickery PD. Grasshopper sparrow (Ammodramus savannarum). In: Poole A, Gill, Eds. The birds of North America. The Birds of North America, Inc: Philadelphia, Pennsylvania 1999.

[61] Whittingham MJ, Krebs JR, Swetnam RD, et al. Should conservation strategies consider spatial generality? Farmland birds show regional not national patterns of habitat association. Ecol Lett 2007; 10: $25-35$.

[62] Herkert JR. The effects of habitat fragmentation on midwestern grassland bird communities. Ecol Appl 1994; 4: 461-71.

[63] Koper N, Schmiegelow FKK. A multi-scaled analysis of avian response to habitat amount and fragmentation in the Canadian dry mixed-grass prairie. Landscape Ecol 2006; 21: 1045-59.

[64] Peach WJ, Lovett LJ, Wotton SR, et al. Countryside stewardship delivers cirl buntings (Emberiza cirlus) in Devon, UK. Biol Conserv 2001; 101: 361-73.

[65] Dimmick RW, Gudlin MJ, McKenzie DF. The northern bobwhite conservation initiative. Miscellaneous publication of the southeastern association of fish and wildlife agencies. Columbia, South Carolina 2002.

[66] Burger LW, McKenzie D, Thackston R, et al. The role of farm policy in achieving large-scale conservation: bobwhite and buffers. Wildl Soc Bull 2006; 34: 986-93.

[67] Herkert JR. Evidence for a recent Henslow's sparrow population increase in Illinois. J Wildl Manage 2007; 71: 1229-33.

[68] Burger LW. Creating wildlife habitat through federal farm programs: an objective-driven approach. Wildl Soc Bull 2006; 34: 994-9.

(C) Riffell et al.; Licensee Bentham Open.

This is an open access article licensed under the terms of the Creative Commons Attribution Non-Commercial License (http://creativecommons.org/licenses/by$\mathrm{nc} / 3.0 /$ ), which permits unrestricted, non-commercial use, distribution and reproduction in any medium, provided the work is properly cited. 